\title{
Carrageenan Extracted from Eucheuma cottonii Through Variant of Drying Time
}

\author{
Novy Pralisa Putri ${ }^{1}$, Ari Susandy Sanjaya ${ }^{1}$, Neli Kartika Sari ${ }^{1}$, Reni Puspita Sari $^{l}$, Yazid Bindar $^{2}$ \\ ${ }^{1}$ Department of Chemical Engineering, Mulawarman University, Jalan Sambaliung 09 Kampus \\ Gunung Kelua, Samarinda 75119, Indonesia E-mail: np.putri@ft.unmul.ac.id \\ ${ }^{2}$ Department of Chemical Engineering, Institute of Technology Bandung, LABTEK X, Jalan \\ Ganesha 10, Bandung 40132, Indonesia
}

\begin{abstract}
Carrageenan is a derivative product of seaweed that used in various fields such as pharmacy, food and cosmetics. One of the most widely used carrageenan from seaweed was Eucheuma cottonii sp. The research was conduct to determine the effect of post-harvest seaweed pretreatment on yields of Carrageenan. The first pre-treatment done by using the fresh seaweed that has been washed clean then directly dried. The second pre-treatment, washed seaweed soaked with clean water for seven days and then dried with a dryer. Drying time for the first and second pretreatments is varied, then dried seaweed extracted with water to produce carrageenan. The analyses performed were moisture content of seaweed and yields of Carrageenan. The results of the research found that the initial moisture content of seaweed on the second pre-treatment was greater than the first pre-treatment. The variation of drying time on the first pretreatment did not affect significantly on the yields, but in the second pretreatment, yield of carageenan increased with accumulation drying time.
\end{abstract}

\section{Introduction}

Indonesia is one of the longest coastline countries, and the Indonesian archipelago is separated by oceans. The Indonesian sea is a huge potential for seaweed development. Indonesia is a major producer of Kappaphycus and Euchema seaweed species, these two types are the main contributors of the carrageenan industry [1]. Indonesia has more than five hundred types of seaweed, some of type are used for base material products. Red algae such as types of Eucheuma, Gelidium, Gracilaria, Hypnea, Sargasum, and Turbinaria which is a type of seaweed that has been widely cultivated in Indonesia [2]. Harvested on seaweed, typically has $90 \%$ water content and need to be dried to achieve the quality specifications from the consumers [3]. In Sabah, Malaysia, there are two types of drying method, platforming and hanging
[4]. This condition almost the same as Indonesia, drying methods use the platform with wood, bamboo, cement and asphalt. The common conventional technique use in Indonesia for drying seaweed was open drying sun. One of disadvantage of this method, seaweed is not good in quality and also the problem of hygienic. The product gets contaminated from dust, insects, rodents, and other animals, which seriously lowering the food quality [5].

Drying kinetics in seaweeds was also studied under these following pre-treatments: open drying and drying at various temperature from $40-90{ }^{\circ} \mathrm{C}$ [6]. From the experiment shows that seaweed drying process that used open sun drying, has took 7 hours to dried, and water content reduce from $94.6 \%$ to $8.33 \%$ [7]. Moisture content, water activity, colour were affected significantly with

\footnotetext{
Corresponding author: novylisa@gmail.com
} 
temperature of drying [8]. For the appropriate temperature, $50 \mathrm{oC}$ was selected as drying temperature.

Carrageenan are sulphated linear polysaccharides of D-galactose and 3,6-anhydro-D-galactose, which have been used in food industry and pharmaceutical industry [9]. Carrageenan from Eucheuma cottonii can be taken through four steps, first step was mixed with sodium hydroxide, then extracted which ratio of 1:30, filtered and precipitated [10]. Extraction of carrageenan also can be made with mixed the water and potassium hydroxide [11]. Beside from Euchema cottonii, carrageenan can also be obtained from Euchema spinosum with ratio solvent 1:20 [12]. However, the aim of the research to determine the effect of pre-treatment and correlation the drying time with characteristics of carrageenan produced

\section{Materials and Methods}

\subsection{Raw material}

Eucheuma cottonii were collected from seaweed cultivated in Manggar, Balikpapan. Seaweed was prepared in two pre-treatments. At first treatment, seaweed washed up to clean the sand and salt, then dried. At second treatment, seaweed that has washed up to clean the sand and salt, then immersed with fresh water that replaced every day. Subsequently seven days, seaweed is drained and dried.

\section{Drying}

The dried seaweed used tray dryer and heat by humid air. Temperature drying used for was $50{ }^{\circ} \mathrm{C}$. Then observed every variant time of 20,40,60, 80, and 100 minutes, especially the of mass losses to determine the water content and the change of colour (physically)

\subsection{Carrageenan extraction}

After reach the desired time, the dried seaweed was extracted to obtaining the carrageenan. The ratio of dried seaweed-solvent used was 1:15 (g/ml). Carrageenan made by mixed $75 \mathrm{~mL}$ solvent with $5 \mathrm{~g}$. then the seaweed soaked in water in 15 minutes. After that filtered then the seaweed extracted. The Volume was kept constant by added hot water. After 3 hours, process of extraction was stopped, then the filtrate from the extraction separated. Filtrate mixed with ethanol $90 \%$. The ratio of the volume of filtrate and ethanol was 3:2 (ml), and so formed hydrocolloid fibres (fibre carrageenan) then wait until 18 hours.
Carrageenan yields (\%) were determined by using the equation below

Yield $=\frac{M_{C}}{M_{d s}} \times 100$

Where

$\mathrm{Mc}$ is the mass of carrageenan extracted (gram)

Mds is the mass of dry seaweed (gram) used for extraction.

\section{Result and discussion}

\subsection{Seaweed properties}

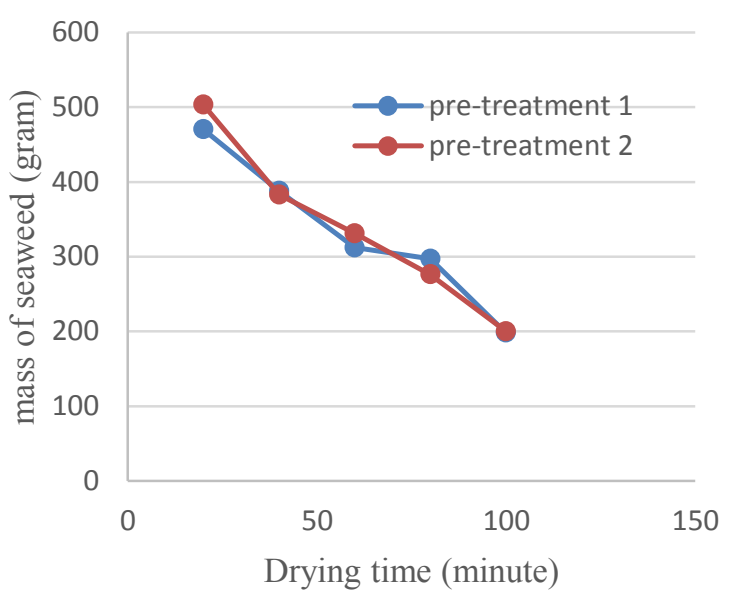

Fig 1. The effect of drying time to mass of seaweed

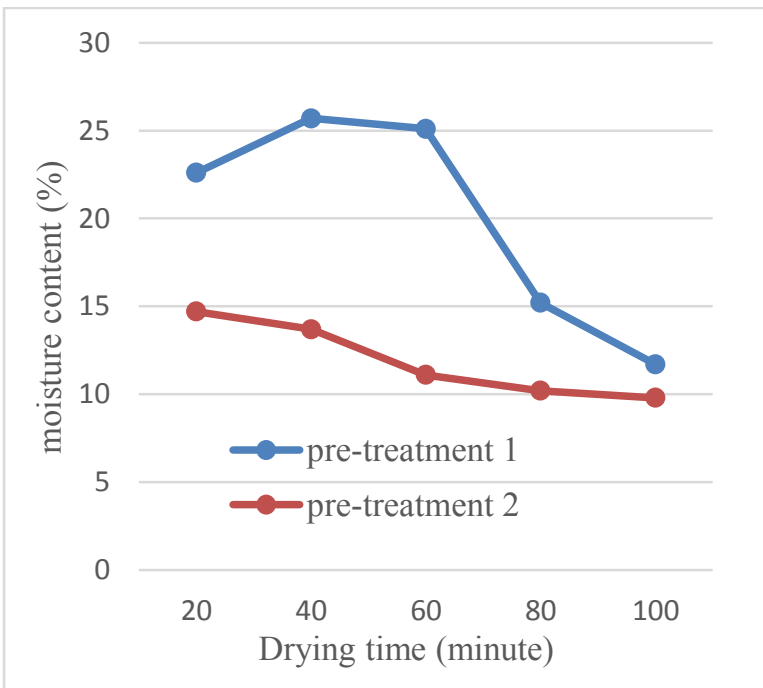

Fig 2. The effect of drying time on moisture content

From Figure 1, it can be found the drying time was inversely proportional to the mass of seaweed, where the higher drying time the lesser mass of seaweed. [7]. 


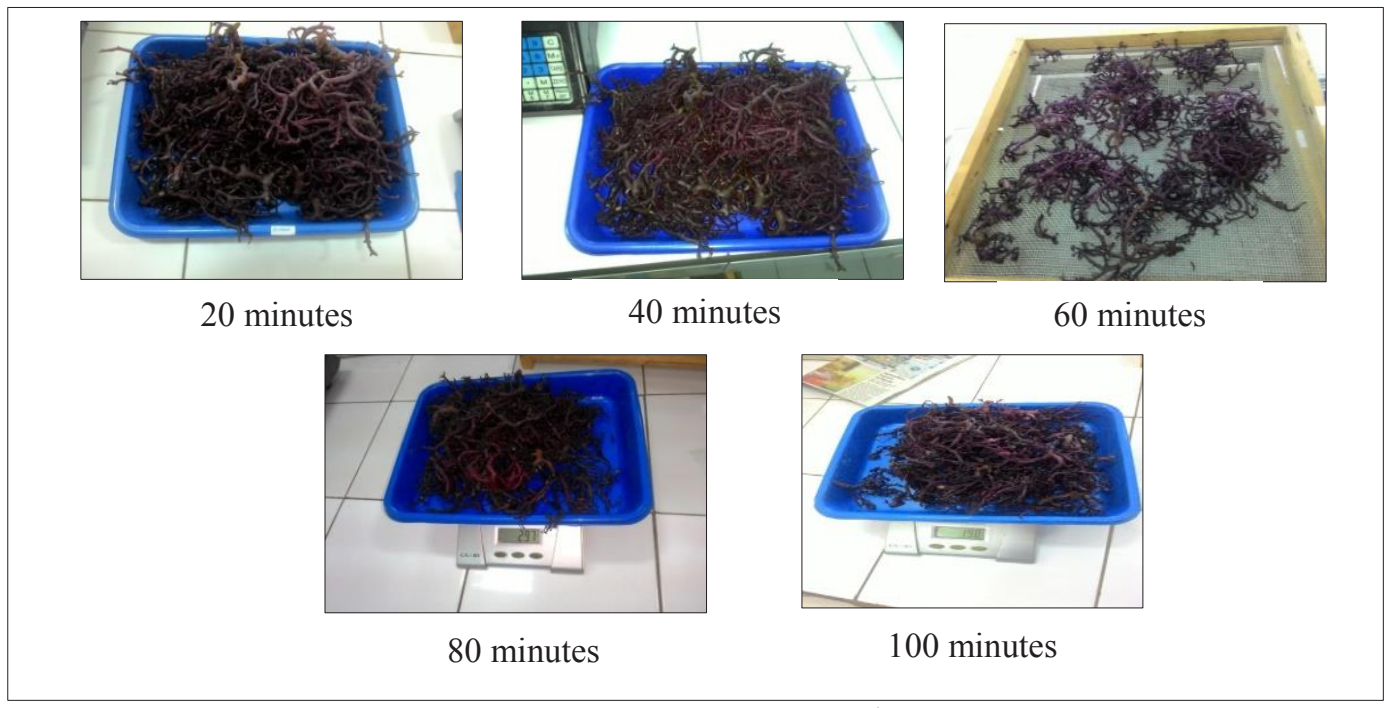

Fig 3. Colour of seaweed after drying $\left(1^{\text {st }}\right.$ pre-treatment $)$

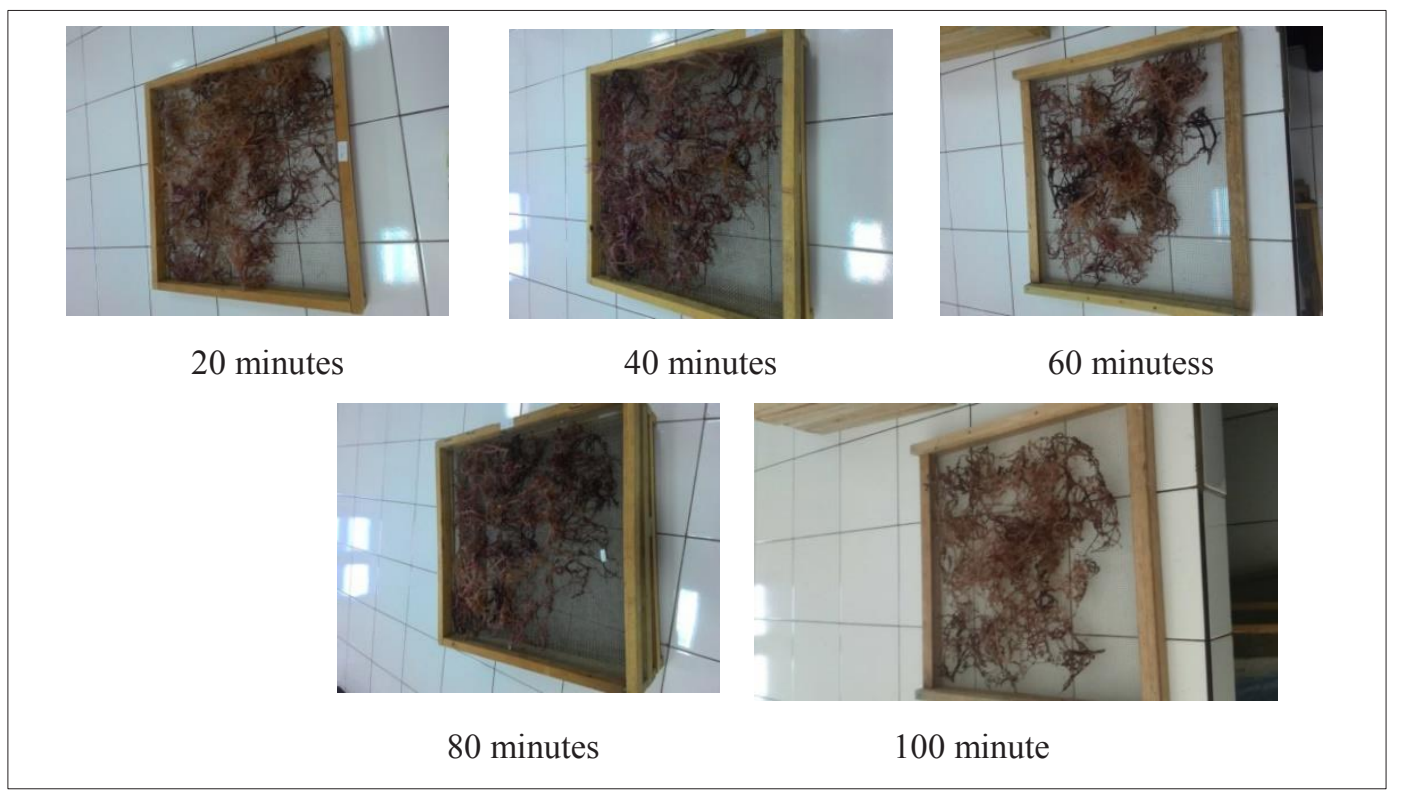

Fig 4. Colour of seaweed after drying $\left(2^{\text {nd }}\right.$ pre-treatment $)$

The results of Figure 2 also show that mass of seaweed on the second treatment at 20 minutes' look higher than the first pre-treatment. This can be occurred due to the moisture content in the seaweed on the second treatment is higher than first treatment. The initial moisture content of the seaweed for the first treatment was $89 \%$ w.b and for second treatment was $90 \%$ w.b.

The effect of drying time to moisture content of Eucheuma cottonii was shown in Figure 2. The moisture content decrease after 20, 40, 60, 80 and 100 minutes. From the experiment was done above, which have strong correlation with the drying processes of other food products $[5,7,8,13,14]$.

One of the high-quality factor from the consumer's point view was the changing of the colour after dried [14]. From Figure 3 it can be show, on pre-treatment 1, after drying, the colour of seaweed changed to purple brown with strong odours. On Figure 4, for pretreatment 2, the colour of seaweed turn into light brownish and less pungent odour. The change of the colour during drying is an indication of severe the drying conditions are related with the pigment composition/concentration [15]. The drying rate at below $60{ }^{\circ} \mathrm{C}$ can cause less browning as the colour changes. The degradation occurs because need the longer time rather than the action of polyphenol oxidase [16].

\subsection{Extraction of Carrageenan from seaweed}

From Figure 5, that can be explain, the process of extraction, the results of yield on the first pre-treatment have tendency same with mass of carrageenan for all variant drying time. However, the amount of the carrageenan on first pre-treatment is greater than the second pre-treatment. This can be occurred because in the second pre-treatment most carrageenan was soluble in water when was soaked. It has been reported that carrageenan fractions are water soluble, and being insoluble in oil or fats, and organic solvents [9] 


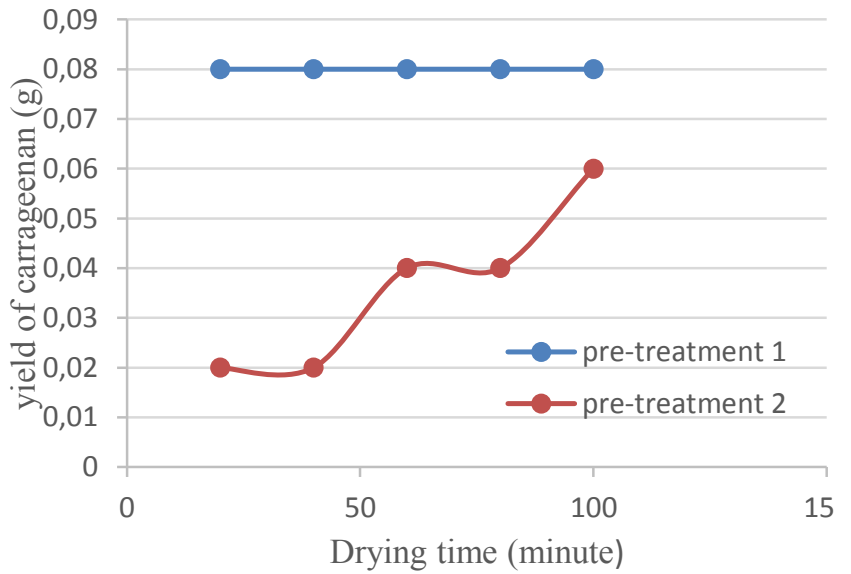

Fig 5. Effect of drying time to mass of carrageenan

\section{Conclusion}

The research shows that the mass of seaweed was found to decline with drying time. The initial moisture content of seaweed on the second pre-treatment was higher than the first pre-treatment. The variant of drying time on the first pre-treatment did not affect significantly on the yields of carageenan. On the second treatment, yield of carageenan increased with accumulation drying time.

\section{References}

1. Harris J. Bixler, H. Porse, A decade of change in the seaweed hydrocolloids industry, J. Appl. Phycol, 23, 321-335 (2011)

2. E. Nugroho, E. Kusnendar, Seaweed agribusiness, (2015) (in Indonesian)

3. M. Djaeni, D.A. Sari, Procedia Environmental Sciences, 23, 2 - 10 (2015)

4. A. Sade, I. Ali, M.R.M. Ariff, The seaweed industry in Sabah East Malaysia, J. Jati, 11, $97-107$ (2006)

5. A. W. Desmukh, M.N. Varma, C.K. Yoo, K.L. Wasewar, Chinese Journal of Engineering, 1 - 7 (2014)

6. G.S. Mattar de Faria, L. Hayashi, A.R. Monteiro, J. Appl Phycol, 26, 917 - 922 (2014)

7. A. Fudholi, M. Y. Othman, M. H. Ruslan, M. Yahya, A. Zaharim, K. Sopian, Design and testing of solar dryer for drying kinetics of seaweed in Malaysia, in Recent Research in Geography, Geology, Energy, Environment and Biomedicine, 119-124 (2011)

8. M.S. Sagrin, G.H. Chong, Industrial Crops and Products, 45, $430-434$ (2013)

9. V.L Campo, D.F. Kawano, D. Braz da Silva Jr, I. Carvalho, Carrageenans: Biological properties, chemical modifications and structural analysis-A review, Carbohydrate Polymers, 77, 167 - 180 (2009)

10. Prasetyowati, C. Jasmine A., D. Agustiawan, Journal of Chemical Engineering 15, 27 - 33 (2008) (In Indonesian)

11. S. Distantina, Fadilah, Rochmadi, $M$. Fahrurrozi, Wiratni, Proceedings Seminar of Chemical Engineering and Process, C-21-1-6 (2010) (In Indonesian)

12. M.I. Hudha, R. Sepdwiyanti, S.D. Sari, J. Periodical Journal Scientific Chemical Engineering 1, 17 - 20 (2012) (In Indonesian)

13. A. B. Siddique, D. Wright, Asian Journal of Plant Sciences, 2 (13), 978 - 982 (2003)

14. S. Kulanthaisami, P. Rajkumar, $P$. Venkatachalam, P. Subramanian, G.S.V. Raghavan, Y. Gariepy, V. Orsat, Maddras Agriculture Journal, 97(7 - 9), 287 - 295 (2010)

15. A. Topuz, H. Feng, M. Kushad, Food Science and Technology, 42, 1667 - 1673 (2009)

16. D. Argyropoulos, J. Müller, Journal of Applied Research on Medicinal and Aromatic Plants, 1 (1), 15-22 (2014) 